\title{
From skin microrelief to wrinkles. An area ripe for investigation
}

\author{
Gérald E Piérard, Isabelle Uhoda \& Claudine Piérard-Franchimont
}

Department of Dermatopathology, University Hospital of Liège, Belgium

\begin{abstract}
Summary
Skin microrelief alters progressively with age. Wrinkles do not result from these changes but are superimposed upon them. Wrinkles result from structural changes in the epidermis, dermis and hypodermis. Four types of wrinkles can be recognized.

Type 1 wrinkles are atrophic.

Type 2 wrinkles are elastotic.

Type 3 wrinkles are expressional.

Type 4 wrinkles are gravitational.

Each type of wrinkle is characterized by distinct microanatomical changes and each type of wrinkle develops in specific skin regions. Each is likely to respond differently to treatment. Skin microrelief and skin folds can be identified on histological examination. By contrast, only minimal dermal changes are found beneath permanent or reducible wrinkles compared with immediately adjacent skin. A series of objective and noninvasive methods is available to quantify the severity of wrinkling.
\end{abstract}

Keywords: wrinkle, ageing, dermis, microrelief, solar elastosis

\section{Introduction}

Regardless of visible changes, skin mirrors the passage of time and the superimposed effects of many endogenous and exogenous threats. ${ }^{1}$ The spectrum of visible changes of the skin surface relief occurring with age may have a precise anatomical support that depends on distinct molecular alterations. Some of the alterations can only be seen from very near. They correspond to modifications in the quality of the horny layer and in the patterning of the skin surface. ${ }^{2}$ Other alterations are more obvious. They are represented by the gross skin topographical changes including folds and wrinkles.

According to Mark Twain wrinkles should merely indicate where smiles have been. Nevertheless these changes can impact dramatically on self-esteem and on Society's

Correspondence: G E Piérard, Department of Dermatopathology, CHU Sart Tilman, B-4000 Liège, Belgium. E-mail: Gerald.Pierard@ulg.ac.be

Accepted for publication 30 October 2003 perception of individuals. Today's youth cult, particularly with its pressure for women to attempt to remain beautiful beyond 40, means that they must depart little from the look of a 25-year-old or younger woman.

\section{Genuine skin microrelief}

Wrinkles correspond to specific alterations of the skin relief that develop with ageing. This does not mean that the skin surface of a young individual is flat. Indeed the skin microrelief depends on both the structure of the dermis and the mechanical forces imposed on the tissue. $^{3,4}$

The genuine microrelief is characterized by typical patterns of intersecting lines and regularly dispersed follicular and eccrine duct openings. Any magnifying lens reveals the remarkable organization of the human skin topography, and the large regional variations from one anatomical site to another. Microscopic examination of cyanoacrylate skin surface strippings better reveals these details. ${ }^{2,5}$ Recently, a device called SkinChip ${ }^{\circledR}$ 
was developed using ST's TouchChips silicon image sensor technology (L'Oréal and STMicroelectronics, Paris). Detailed non-optical images of the skin topography are captured by the sensor which generates a capacitance map of the skin surface. This non-invasive equipment works under any skin or environmental conditions.

The different aspects of the skin microrelief are generally classified according to the orientation and depth of lines. ${ }^{5-7}$ The primary and secondary lines are discrete and shallow, respectively, reaching $20-200 \mu \mathrm{m}$ in depth. They form a criss-cross pattern delimiting various polygonal plateaus. They are particularly well marked on the wrists and forearms. The tertiary lines are invisible at the naked eye. They correspond to the edges of corneocytes. The quaternary lines are also exceedingly thin, forming a discrete trabecular network on the corneocyte membrane itself.

The microrelief characteristics of the primary lines depend on the structure of the papillary dermis. ${ }^{3}$ It conditions such factors as the skin softness and its velvety aspect. The mean depth of these primary lines does not change from birth until adult life. However, their orientation and depth differ according to the body site, and change with ageing and under the influence of some environmental factors. ${ }^{2,5-8}$ The innate polygonal pattern becomes more anisotropic (Fig. 1) and the so-called 'coefficient of developed skin surface' increases $^{4}$ and the 'irregularity skin index' as well. ${ }^{9}$ These changes are associated with progressive density loss and atrophy of the reticular dermis, decreased elasticity and increased skin folding capacity. ${ }^{10,11}$ They precede the loose crinkling of atrophic skin which is common in the elderly.

\section{Wrinkles and skin ageing}

Wrinkles as a sign of cutaneous ageing may cause cosmetic disability and psychological distress. They are part of ageing which has both intrinsic and extrinsic components. ${ }^{12}$ These effects are often intermingled. ${ }^{1}$ The former refers to presumed genetically programmed together with attritional changes at both covered and exposed sites. It manifests clinically as dermal thinning with decreased elasticity. With ageing, collagen bundles become thinner and widely separated from each other, apparently heaped in an haphazard way. The lateral cohesiveness between individual collagen fibrils is also weakened. The elastic fibres form horizontally orientated arcades. From these arcades, perpendicularly orientated fibres rise toward the surface. They usually branch, fuse with adjoining fibres, and form thinner arcades. From
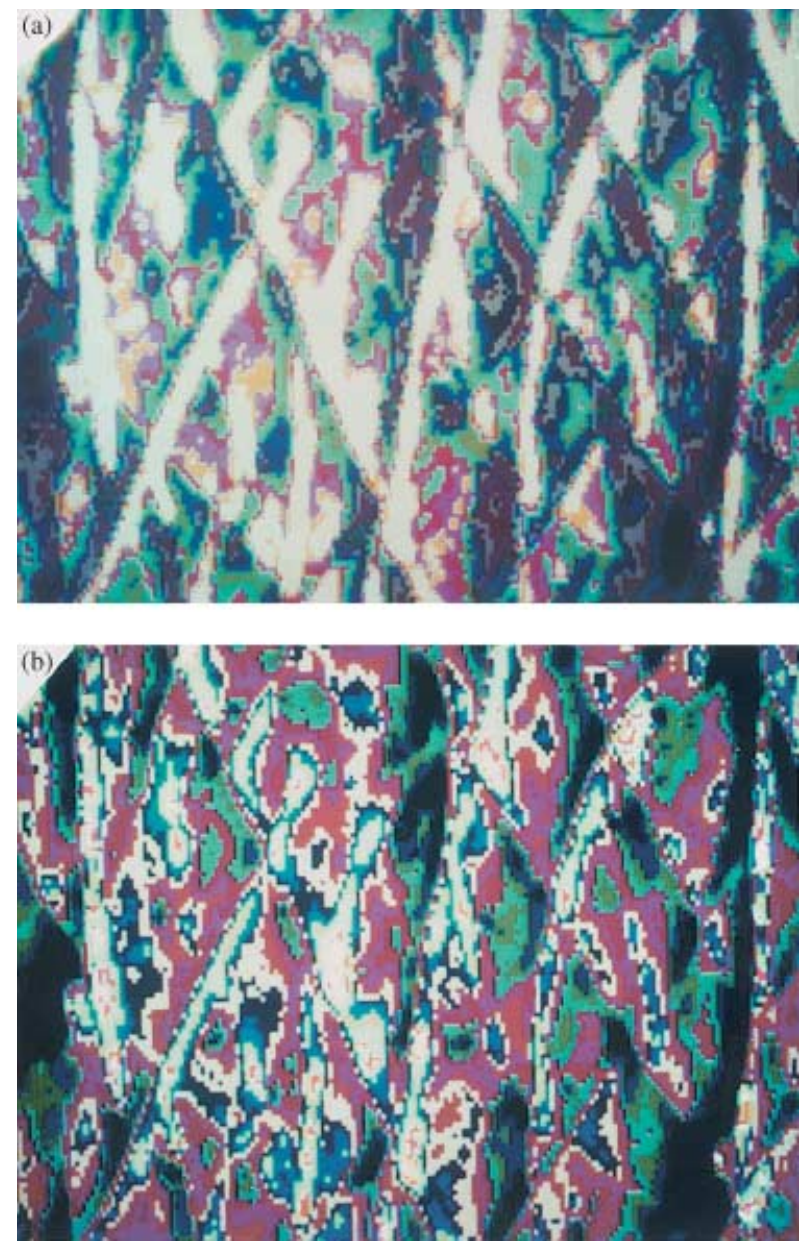

Figure 1 Effect of repeated intense ultraviolet light on the microrelief of the skin of two female twins aged 46. False colour image analysis emphasizes the effects of photodamage. (a) Preserved criss-cross pattern of primary and secondary lines in the twin who avoided the sun. (b) Altered pattern in the other twin who regularly attended a tanning parlour for two decades.

this meshwork, fine terminal vertical fibres point to the dermo-epidermal junction. The vertically orientated fibres in the papillary dermis outline different patterns in different body regions. Long fibres may branch in a selfreplicating pattern toward the epidermis, where they form long penicillate endings. This overall pattern becomes progressively disorganized with ageing. The dermal density in mast cells and dendrocytes markedly decreases with age on sun-protected areas. Proteoglycans may appear slightly decreased.

Extrinsic skin ageing, called photoageing or dermatoheliosis, affects chronically ultraviolet light-exposed sites. It is thought to be mainly due to physical factors 
principally sunlight. ${ }^{1,12-14}$ The clinical effects of actinic insult may remain inapparent for decades after the initial structural damage. ${ }^{15}$ In time, avid sun worshippers develop inexorably a variety of fine and coarse wrinkling, yellowness, laxness, leatheriness, roughness, telangiectasia, mottled pigmentation and actinic keratoses. These features of photoageing often differ among individuals despite similar sun exposure. ${ }^{16}$ The phototypes and ethnic characteristics play prominent roles in the gross clinical presentation.

Chronically sun-exposed skin shows disorganization of the stratum Malpighi, cytological atypia of keratinocytes, and irregular melanin distribution in the basal layers of the epidermis. Dermal elastosis is the key feature with loss of the regular network of collagen bundles and accumulation of basophilic fibres in the upper reticular dermis. ${ }^{17}$ They largely correspond to abnormally overgrown elastic fibres, but their precise biochemical composition is not completely identified. Solar elastosis contains a combination of microfibrils and amorphous elastin. Antibodies directed to fibrillin, decay-accelerating factor, serum amyloid proteins and recombinant tropoelastin bind to this material that is also covered by lysozyme and immunoglobulins. ${ }^{18-22}$ Wherever there is great accumulation of enlarged, knotted and diffused elastotic masses, some breakdown of fibres is also present. ${ }^{23}$ Such a fibrorrhexis is commonly accompanied by a macrophage and dendrocyte infiltration. It is unclear how much solar elastosis is in a state of dynamic flux, fragmenting and being resorbed while being replaced. Nevertheless, increased elastin mRNA levels in photoaged skin, as well as increased elastin and fibrillin mRNAs in skin explant-derived fibroblasts are operative. ${ }^{24,25}$ Furthermore, marked enhancement of elastin promoter activity is present in fibroblasts. This suggests that enhanced elastin and fibrillin gene expression is associated with the changes typical for solar elastosis.

Matrix-degrading metalloproteinases (MMP) mRNAs, proteins and activities are induced in human skin in vivo within hours after exposure to ultraviolet (UV)-B irradiation. ${ }^{26}$ Furthermore, low-dose UVB up-regulates the transcription factors AP-1 and NF- $\mathrm{KB}$, which stimulate MMP genes. Elevated MMP, resulting from activation of AP-1 and NF-KB by low-dose irradiation degrade collagen and elastin in skin. ${ }^{27-30}$ UVA-induced autocrine stimulation of fibroblast-derived collagenase by IL- 6 may also contribute to the actinic damage of the dermis. As a consequence, sun-exposed skin is characterized by a decrease in collagen types I, III and VII. ${ }^{25,31,32}$ The last reduction is responsible for lowering the number of anchoring fibrils at the dermo-epidermal junction. ${ }^{32}$ The microfibrillar type VI collagen necessary for cell-cell and cell-matrix communications appears to be relatively unaffected by the photoageing process. ${ }^{33}$ In addition to the changes in some collagen types ${ }^{34,35}$ in the superficial dermis, there is also a loss of fibrillinrich microfibrils in this region. ${ }^{36}$ By contrast, there is enhanced expression of tenascin at the same sites. Mast cells and dendrocytes are plump and probably hyperactive.

Factors including hormonal disturbances (e.g. menopause, Cushing syndrome, acromegaly and hypothyroidism) diverse xenobiotics (e.g. photosensitizers, irritants and topical corticosteroids) and the smoking habit among others also affect the clinical and histological presentation of ageing. ${ }^{10,37-41}$ To cope with such diversity, seven types of cutaneous ageing have been described. ${ }^{1}$ They are listed in the present issue of the Journal. ${ }^{42}$

\section{Wrinkle classification}

Wrinkles do not simply represent the deepening of the shallow lines forming the genuine microrelief. They are readily visible and are much deeper and less numerous than the primary lines. It has been proposed that the term wrinkle should apply when an extension of the skin perpendicular to the axis of the skin surface change leaves a marked line representing the bottom of the wrinkle. ${ }^{16}$ However, the literature appears quite confusing because there is no consensus about the definition of such terms as wrinkle, rhytide, crinkle, crease, groove, line and furrow. The same difficulty is encountered in their descriptive rating including fine, shallow, small, thin, coarse, and still other terms. Several systems of clinical and instrumental assessments have been recently revisited to fine-tune the assessments. ${ }^{7,43-45}$

The face is the part of the body most visible to others, and its wrinkles are a hallmark of ageing. There is great confusion and sometimes controversy about the biological origins and consequences of wrinkles, and about their microanatomical basis. ${ }^{46-50}$ Indeed, relatively little is known about the cellular implications in wrinkling. Four basic types of wrinkles can be distinguished according to their histological aspects and pathogenesis. ${ }^{45}$ The most profound structural differences between them are found in the dermis and hypodermis. There is only a limited contribution of the epidermis, which may be discretely thinned in the bottom of permanent wrinkles. The sequence of changes occurring over decades including the end-stage alterations are qualitatively very different among the wrinkle types. In addition, these telltale signs of age do not respond to the same treatments. This implies that the results of a clinical trial performed on one specific 


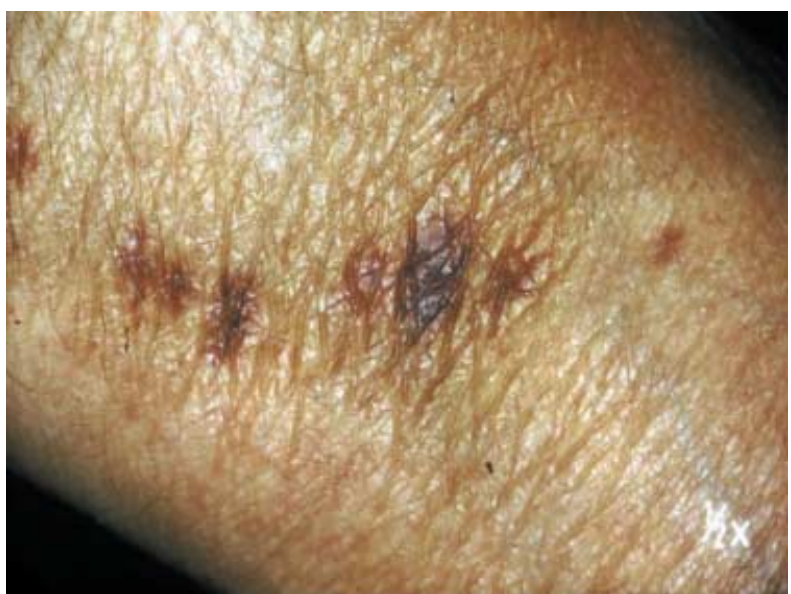

Figure 2 Type 1 wrinkles due to atrophy.

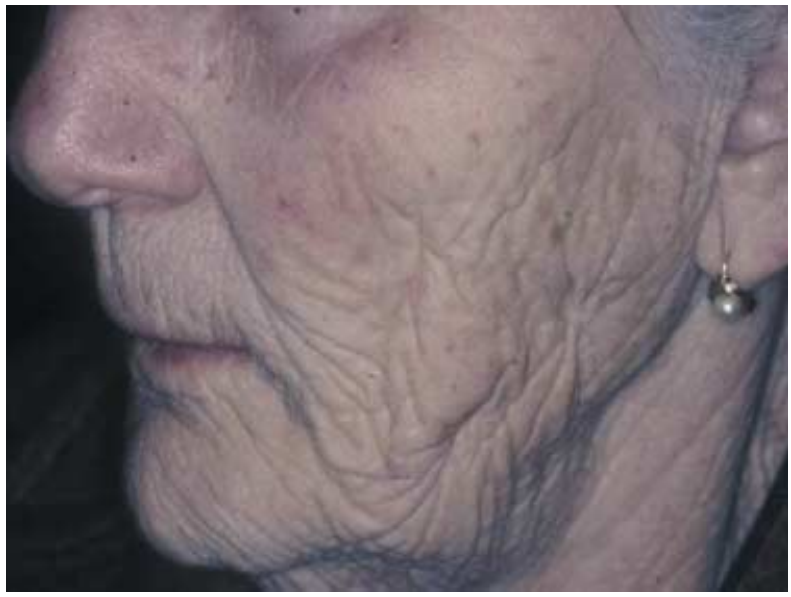

Figure 3 Type 2 wrinkles due to solar elastosis.

type of wrinkle cannot be extrapolated with confidence to the other wrinkle types.

Type 1 wrinkles (atrophic) are fine, almost parallel each other, and they vanish when skin is put under transversal tension (Fig. 2). These crinkling wrinkles correspond to worn-looking skin foldings which easily change in shape and orientation with the body posture. ${ }^{45,46}$ They are due to the atrophy of the collagen bundles both in the reticular dermis and the hypodermal connective tissue strands. Solar elastosis may be present, but then only as a loose network. It may also be absent on sun-protected areas. The presence of these wrinkles is always associated with impaired mechanical properties of the skin with increased extensibility and decreased elasticity. ${ }^{10}$

Type 2 wrinkles (elastotic) become progressively permanent lines, developed on certain sun-exposed skin areas where solar elastosis is hypertrophic, compact

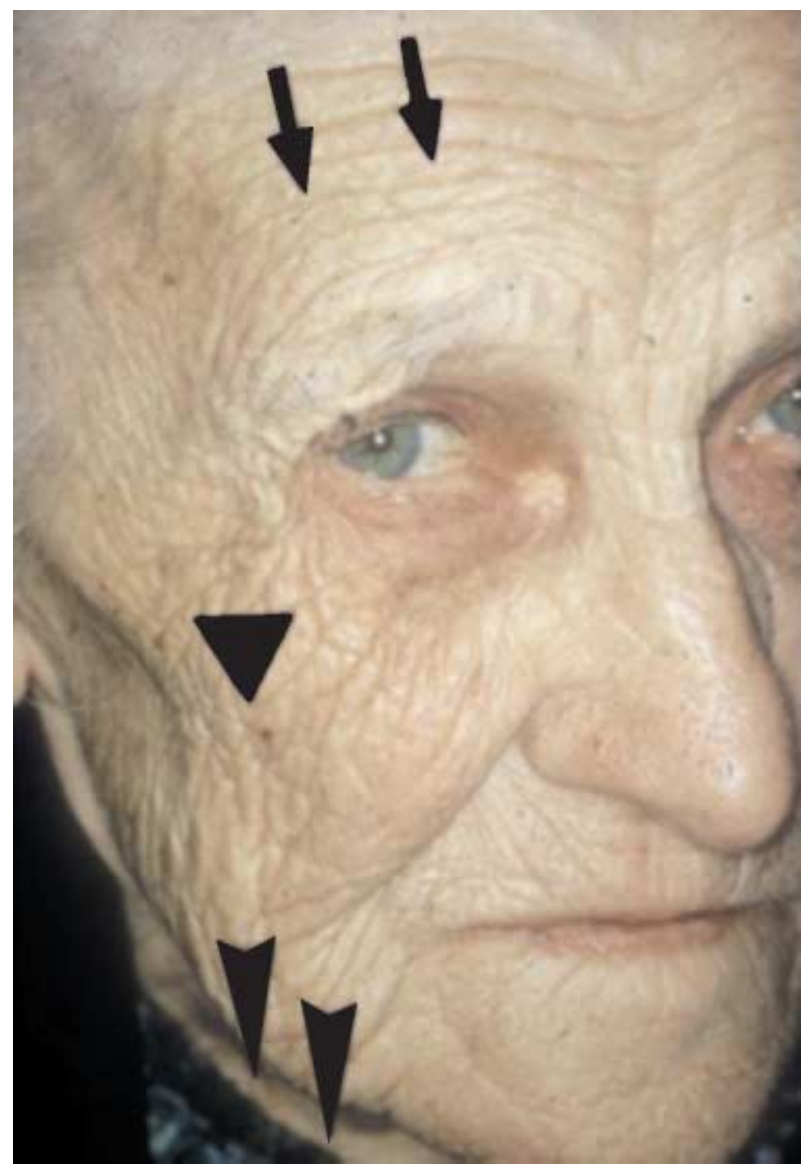

Figure 4 Type 3 wrinkles due to expression lines on the forehead, and type 4 wrinkles due to gravity near the lower mandible.

and largely overcompensating in volume the collagen atrophy. They are typically found on the cheeks, upper lip and neck. When fully developed, they do not vanish under skin stretching perpendicularly to the wrinkle axis. The orderly patterning of the epidermal surface is lost and replaced by a criss-cross and rhomboidal pattern (Fig. 3). A thick and compact solar elastosis is present between these wrinkles. It represents a cobblestonelike sequestrated material making the skin more rigid. The accumulation of actinic elastosis may be markedly increased below the permanent wrinkles compared to the reducible wrinkles. ${ }^{50}$ This type of wrinkle is much less prominent in people with darker skin than in Caucasians.

Type 3 wrinkles (expressional) become permanent lines, always orientated in a stereotyped pattern according to the forces imposed by facial muscles (Fig. 4). The frown lines, the glabellar lines and the crow-feet wrinkles are typical examples. Their anatomical origin is located in the hypodermal connective tissue strands harbouring 
muscle cells. Repeated contractions exerted at the same anatomical sites by facial expression is accompanied by a thickening and shortening of these structures, maintaining a strong hidebinding of the skin to the underlying rigid structures. ${ }^{47}$ Botulinum toxin, which releases muscular tension, helps these specific wrinkles to disappear.

Type 4 wrinkles (gravitational) result from gravitational forces inducing folding and sagging of skin which has lost its turgidity (Fig. 4). The main structural changes consist of a loosely remodelled fibrous network in the hypodermis. It is worth noting that these deformations predominate at locations where the thickness of the hypodermis has been important before people lose weight during adulthood. Thus, a fat face has fewer wrinkles than a lean one. It can be assumed that constant unidirectional forces applied to the connective tissue strands in the hypodermis allow their progressive extension followed by a similar increase in size of the reticular dermis. The same phenomenon occurs in flexural lines created by body posture. These gravitational and flexural folds disappear with the skin lifting procedures.

Damages to human skin due to passage of time and to repeated exposure to ultraviolet light are considered distinct entities. ${ }^{12}$ However, the latter influence is responsible for stress-induced premature senescence (SIPS) in cells, including fibroblasts and melanocytes. Hence, the boundary between the two conditions is somewhat blurred. When considering wrinkles, both intrinsic and
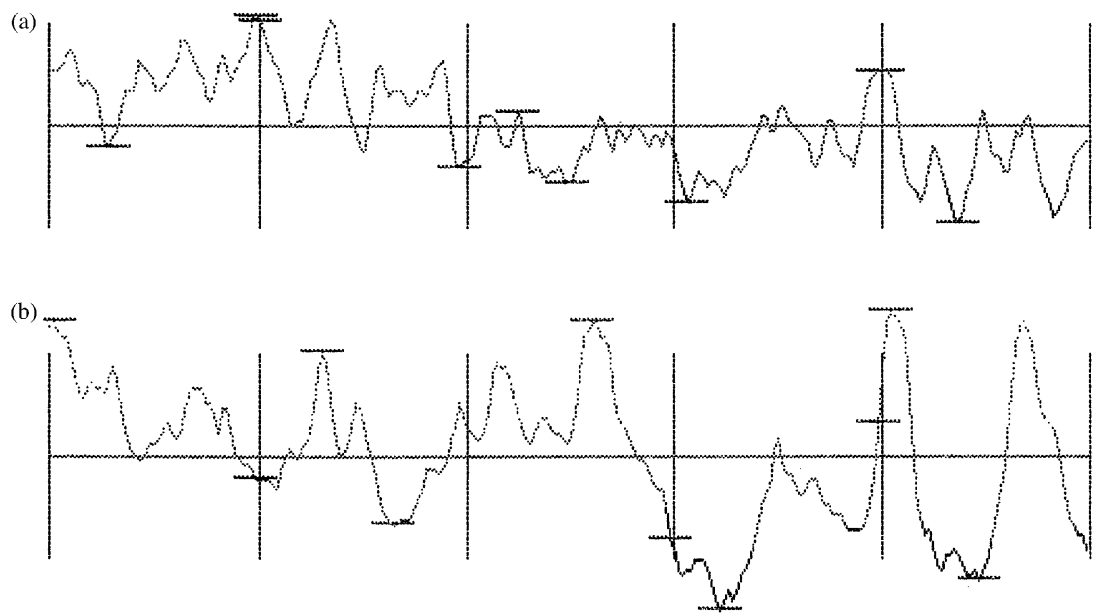

(c)

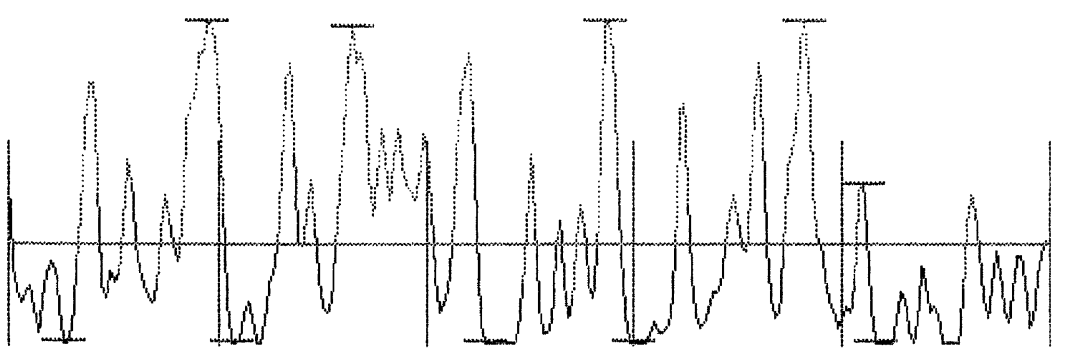

Figure 5 Profilometry of different skin surfaces. Ra and $\mathrm{Rz}$ are two standardized profilometric measures whose values increase with the wrinkling severity.

(a) Smooth surface, Ra: 8, Rz: 25.

(b) Crinkling wrinkles, Ra: 12, Rz: 39.

(c) Actinic wrinkles, Ra: 17, Rz: 57.

(d) Expression wrinkles, Ra: 12, Rz: 60.

(d)

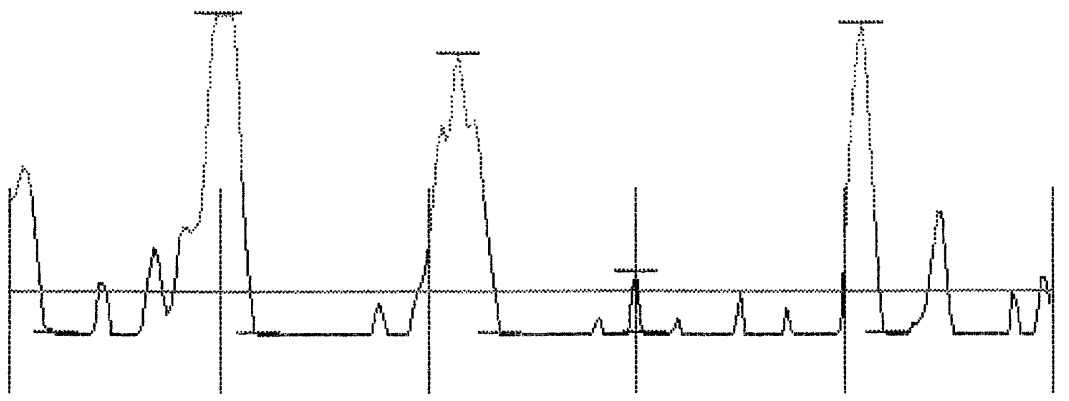


photo-induced ageing processes are obviously involved in their pathogenesis. ${ }^{45,51}$ However, mechanical forces also play a pivotal role. Furthermore, once a primary pathomechanism is operative, consequences at the biological level involve other secondary processes as well. ${ }^{15}$ Hence, any wrinkle does not depend on one single physiopathological process, but rather results from a combination of complex interrelated mechanisms which in turn alter distinctly the connective tissue microarchitecture. ${ }^{45,51,52}$ However, it remains essential to determine the principal aetiology of wrinkles if one is to design the proper treatment protocol for the patient seeking corrective procedures. The prospect of becoming old and wrinkled brings little joy to most people. However, the seemingly lack of correlation between wrinkling and skin cancer $^{53}$ may bring a possible silver lining to this grey cloud.

\section{Wrinkle assessment}

Wrinkles can be classified according to their visual presentation. ${ }^{7,16,43}$ Rating scales can be used to assess their severity of expression (Table 1). Several noninvasive bioengineering methods are currently available to make precise quantifications. ${ }^{4,7,8,41,54-63}$ The most common approach for measuring the geometric properties of human skin is to transfer the details of the skin topography to a material suitable for the selected method of measurement. Various measuring instruments and systems have been developed to gauge these replias (Fig. 5). Other newer methods are available, including topometry and fringe image analysis in vivo. These methods were extensively reviewed by the EEMCO group. $^{7}$

The physiological and structural changes associated with ageing skin are varied. ${ }^{63}$ The development of crinkles and wrinkles on the face is sometimes attributed to the effects of photoageing. This contention is only valid for some specific types of wrinkles. Regional variability between sun-exposed parts of the body may be quite prominent when solar elastosis and wrinkles are considered. Skin is indeed very different on the face and

Table 1 Clinical scoring of facial wrinkles.

\begin{tabular}{ll}
\hline Score & Wrinkle appearance \\
\hline 0 & None \\
1 & Faint \\
2 & Shallow \\
3 & Few but obvious \\
4 & Dense network \\
\hline
\end{tabular}

on the dorsal forearm. When solar elastosis is thick and compact on the face, it often remains loose and delicate on the forearms. Some effects of cosmetic treatments can thus be evident on one site and remain deceptive on the other.

\section{Conclusion}

Physiologists are aware of the genuine skin microrelief. People who are progressively leaving youth do not care about this aspect. However, when they perceive the earliest wrinkles, some of them fear the future and start to fight wrinkles. It is obvious that the wrinkled aspect varies among individuals of the same age. Indeed, it is due to the combination of several distinct pathomechanisms, because the skin surface is exposed to numerous influences that can cause visible changes in its microtopography. The recognition of four types of wrinkles may be a springboard for better targeting them by appropriate dermo-cosmetic means. The objective assessment using bioengineering methods can help in documenting individual cases and in supporting claims about treatment procedures. In the overall, avoiding the onslaught of the sun stays off some grotesqueries but ultimately everyone falls prey to wasting disasters before the coming of the Reaper.

\section{References}

1 Piérard GE. The quandary of climacteric skin aging. Dermatology 1996; 193: 273-4.

2 Lavker RM, Kwong F, Kligman AM. Changes in skin surface patterns with age. J Gerontol 1980; 35: 348-54.

3 Piérard GE, Hermanns JF, Lapière $\mathrm{CH}$. Stéréologie de l'interface dermo-épidermique. Dermatologica 1974; 149: 266-73.

4 Piérard GE, Piérard-Franchimont C, eds. The Dermis from Biology to Diseases. Liège: Monographies dermatopathologiques liégeoises; 1989: pp. 102-13.

5 Piérard-Franchimont C, Piérard GE. Assessment of aging and actinic damages by cyanoacrylate skin surface strippings. Am J Dermatopathol 1987; 9: 500-9.

6 Piérard GE. EEMCO guidance for the assessment of dry skin (xerosis) and ichthyosis: evaluation by stratum corneum strippings. Skin Res Technol 1996; 2: 3-11.

7 Lévêque JL. EEMCO guidance for the assessment of skin topography. J Eur Acad Dermatol Venereol 1999; 12: 103-14.

8 Corcuff P, Francois AM, Lévêque JL, Porte G. Microrelief changes in chronically sun-exposed human skin. Photodermatol 1988; 5: 92-5.

9 Setaro M, Sparavigna A. Irregularity skin index (ISI): a tool to evaluate skin surface texture. Skin Res Technol 2001; 7: 159-63. 
10 Piérard GE, the EEMCO group. EEMCO guidance to the in vivo assessment of tensile functional properties of the skin. Skin Pharmacol Appl Skin Physiol 1999; 12: 352-62.

11 Batisse D, Bazin R, Baldeweck T, Querleux B, Lévêque JL. Influence of age on the wrinkling capacities of skin. Skin Res Technol 2002; 8: 148-54.

12 Gilchrest BA. Skin aging and photoaging: an overview. J Am Acad Dermatol 1989; 21: 610-3.

13 Scharffetter-Kochanek K, Brenneisen P, Wenk J, Hermann G, Ma W, Kuhr L, Meewes C, Wlaschek M. Photoaging of the skin from phenotype to mechanisms. Exp Gerontol 2000; 35: 307-16.

14 Ma W, Wlaschek M, Tantcheva-Poor I, Schneider LA, Naderi L, Razi-Wolf Z, Schuller J, Scharffetter-Kochanek K. Chronological ageing and photoageing of the fibroblast and the dermal connective tissue. Clin Exp Dermatol 2001; 26: 592-9.

15 Hermanns JF, Petit L, Piérard-Franchimont C, Cauwenbergh G, Piérard GE. Unraveling the patterns of subclinical phaeomelanin-enriched facial hyperpigmentation. Effect of depigmenting agents. Dermatology 2000; 201: 118-22.

16 Griffiths CE. The clinical identification and quantification of photodamage. Br J Dermatol 1992; 127 (Suppl. 41): 37-42.

17 Bhawan J, Oh CH, Lew R, Nehal KS, Labadie RR, Tsay A, Gilchrest BA. Histopathologic differences in the photoaging process in facial versus arm skin. Am J Dermatopathol 1992; 14: 224-30.

18 Chen VL, Fleishmajer R, Schwartz E, Palaia M, Timpl R. Immunochemistry of elastotic material in sun-damaged skin. J Invest Dermatol 1986; 87: 334-7.

19 Mera SL, Lovell CR, Russel Jones R, Davies JD. Elastic fibres in normal and sundamaged skin: an immunohistochemical study. Br J Dermatol 1987; 117: 21-7.

20 Albrecht S, Kahn HJ. Lysozyme in abnormal elastic fibers of cutaneous aging, solar elastosis, and pseudoxanthoma elasticum. J Cutan Pathol 1991; 18: 75-80.

21 Park PW, Biedermann K, Mecham L, Bisset DL, Mecham RP. Lysozyme binds to elastin and protects elastin from elastase-mediated degradation. J Invest Dermatol 1996; 106: $1075-80$.

22 Piérard-Franchimont C, Uhoda I, Saint-Léger D, Loussouarn G, Piérard GE. Androgenic alopecia and stressinduced premature senescence by cumulative ultraviolet light exposure. Exog Dermatol 2002; 1: 203-6.

23 Suwabe H, Serizawa A, Kajiwara H, Ohkido M, Tsutsumi Y. Degenerative processes of elastic fibers in sun-protected and sun-exposed skin: immunoelectron microscopic observation of elastin, fibrillin-1, amyloid P component, lysozyme and alpha 1-antitrypsin. Pathol Int 1999; 49: 391-402.

24 Mauviel A, Uitto J. Enhanced elastin and fibrillin gene expression in chronically photodamaged skin. J Invest Dermatol 1994; 103: 182-6.

25 Bernstein EF, Brown DB, Urbach F, Forbes D, Del Monaco M, Wu M, Katchman SD, Uitto J. Ultraviolet radiation activated the human elastin promoter in transgenic mice: a novel in vivo and in vitro model of cutaneous photoageing. J Invest Dermatol 1995; 105: 269-73.

26 Fisher GJ, Datta SC, Talwar HS, Wang ZQ, Varani J, Kang S, Voorhees JJ. Molecular basis of sun-induced premature skin ageing and retinoid antagonism. Nature 1996; 379: 335-9.

27 Scharffetter K, Wlaschek M, Hogg A, Bolsen K, Schothorst A, Goerz G, Krieg T, Plewig G. UVA irradiation induces collagenase in human dermal fibroblasts in vitro and in vivo. Arch Dermatol Res 1991; 283: 506-11.

28 Saarialho-Kere U, Kerkela E, Jeskanen L, Hasan T, Pierce R, Starcher B, Raudasoja R, Ranki A, Oikarinen A, Vaalamo M. Accumulation of matrilysin (MMP-7) and macrophage metalloelastase (MMP-12) in actinic damage. J Invest Dermatol 1999; 113: 664-72.

29 Ohnishi Y, Tajima S, Akiyama M, Ishibashi A, Kobayashi R, Horii I. Expression of elastin-related proteins and matrix metalloproteinases in actinic elastosis of sun-damaged skin. Arch Dermatol Res 2000; 292: 27-31.

30 Tsuji N, Moriwaki S, Suzuki Y, Takema Y, Imokawa G. The role of elastases secreted by fibroblasts in wrinkle formation: implication through selective inhibition of elastase activity. Photochem Photobiol 2001; 74: 283-90.

31 Talwar HS, Griffiths CEM, Fisher GJ, Hamilton TA, Voorhees JJ. Reduced type I and III procollagens in photodamaged adult human skin. J Invest Dermatol 1995; 105: 285-90.

32 Craven NM, Watson REB, Jones CJP, Shuttleworth CA, Kielty CM, Griffiths CEM. Clinical features of photodamaged human skin are associated with a reduction in collagen VII. Br J Dermatol 1997; 137: 344-50.

33 Watson REB, Ball SG, Craven NM, Boorsma J, East CL, Shuttleworth CA, Kielty CM, Griffiths CE. Distribution and expression of type VI collagen in photoaged skin. $\mathrm{Br} J$ Dermatol 2001; 144: 751-9.

34 Bernstein EF, Chen YQ, KoppJB, Fisher L, Brown DB, Hahn PJ, Robey FA, Lakkakorpi J, Uitto J. Long-term sun exposure alters the collagen of the papillary dermis. Comparison of sun-protected and photoaged skin by northern analysis, immunohistochemical staining, and confocal laser scanning microscopy. J Am Acad Dermatol 1996; 34: 209-18.

35 Chung JH, Seo JY, Choi HR, Lee MK, Youn CS, Rhie G, Cho KH, Kim KH, Park KC, Eun HC. Modulation of skin collagen metabolism in aged and photoaged human skin in vivo. J Invest Dermatol 2001; 117: 1218-24.

36 Watson R, Griffiths C, Craven N, Shuttleworth A, Kielty C. Fibrillin-rich microfibrils are reduced in photoaged skin. Distribution at the dermal-epidermal junction. J Invest Dermatol 1999; 112: 782-7.

37 Castelo-Branco C, Figueras F, de Osaba MJM, Vanrell JA. Facial wrinkling in postmenopausal women. Effects of smoking status and hormone replacement therapy. Maturitas 1998; 29: 75-86.

38 Boyd AS, Stasko T, King LE, Cameron GS, Pearse AD, Gaskell SA. Cigarette smoking-associated elastotic changes in the skin. J Am Acad Dermatol 1999; 41: 23-6. 
39 Lahmann C, Bemann J, Harrison G, Young AR. Matrix metalloproteinase-1 and skin aging in smokers. Lancet 2001; 24: 935-6.

40 Piérard GE, Piérard-Franchimont C, Vanderplaetsen S, Franchimont N, Gaspard U, Malaise M. Relationships between bone mass density and tensile strength of the skin in women. Eur J Clin Invest 2001; 31: 731-5.

41 Koh JS, Kang H, Choi SW, Kim HO. Cigarette smoking associated with premature facial wrinkling: image analysis of facial skin replicas. Int J Dermatol 2002; 41: 21-7.

42 Piérard GE. Ageing across the life span: time to think again. J Cosmet Dermatol (in press).

43 Lemperle G, Holmes RE, Cohen SR, Lemperle SM. A classification of facial wrinkles. Plast Reconstr Surg 2001; 108: 1735-50.

44 Piérard GE. Instrumental evaluation of anti-wrinkle activity of cosmetic products. What's new?. J Eur Acad Dermatol Venereol 2001; 15: 194-5.

45 Piérard GE, Uhoda I, Piérard-Franchimont C. Update in the histological presentation of facial wrinkles. Eur J Dermatol 2002; 12: S13-4.

46 Kligman AM, Zheng P, Lavker RM. The anatomy and pathogenesis of wrinkles. Br J Dermatol 1985; 113: 37-42.

47 Tsuji T, Yorifuji T, Hayashi Y, Hamada T. Light and scanning electron microscopic studies on wrinkles in aged persons' skin. Br J Dermatol 1986; 114: 329-35.

48 Piérard GE, Lapière ChM. The microanatomical basis of facial frown lines. Arch Dermatol 1989; 125: 1090-2.

49 Contet-Andonneau JL, Jeanmaire C, Pauly G. A histological study of human wrinkle structures: comparison between sun-exposed areas of the face, with or without wrinkles, and sun-protected areas. Br J Dermatol 1999; 140: 1038-47.

50 Bosset S, Barré P, Chalon A, Kurfurst R, Bonté F, André P, Perrier P, Diant F, Le Varlet B, Nicolas JF. Skin ageing clinical and histopathologic study of permanent and reducible wrinkles. Eur J Dermatol 2002; 12: 247-52.

51 Nagashima H, Hanada K, Hashimoto I. Correlation of skin phototype with facial wrinkle formation. Photodermatol Photoimmunol Photomed 1999; 15: 2-6.
52 Rao BK, Endzweig CH, Kagen MH, Kriegel D, Freeman RG. Wrinkling due to mid-dermal elasolysis: two cases and literature review. J Cutan Med Surg 2000; 4: 40-4.

53 Brooke RCC, Newbold SA, Telfer NR, Griffiths CEM. Discordance between facial wrinkling and the presence of basal cell carcinoma. Arch Dermatol 2001; 137: 751-4.

54 Grove GL, Grove JM, Leyden JJ, Lufrano L, Schwab B, Perry BH, Thorne EG. Skin replica analysis of photodamaged skin after therapy with tretinoin emollient cream. J Am Acad Dermatol 1991; 25: 231-7.

55 Assoul M, Zahidi M, Corcuff P, Mignot J. Three dimensional measurements of skin surface topography by triangulation with a new laser profilometer. J Med Engineering Technol 1994; 18: 11-21.

56 Piérard GE, Piérard-Franchimont C. Fractal microrelief of the skin and nail. Gior Int Dermatol Ped 1996; 8: 75-9.

57 Potorac AD, Toma I, Mignot J. In vivo skin relief measurement using a new optical profilometer. Skin Res Technol 1996; 2: 64-9.

58 Mignot J, Chuard M, Nita D, Sofa M. 3-D profilometer using a CCD linear image sensor: application to skin surface topography measurement. Skin Res Technol 1998; 4: 121-9.

59 Jaspers S, Hopermann H, Sauermann G, Hoppe U, Lunderstädt R, Ennen J. Rapid in vivo measurement of the topography of human skin by active image triangulation using a digital micromirror device. Skin Res Technol 1999; 5: 195-207.

60 Lagarde JM, Rouvrais C, Black D, Diridollou S, Gall Y. Skin topography measurement by interference fringe projection: a technical validation. Skin Res Technol 2001; 7: 112-21.

61 Lévêque JL. Quantitative assessment of skin aging. Clin Geriat Med 2001; 17: 673-89.

62 Mazzarello V, Cametti M, Leone G, Iacovelli P, Ena P, Leigheb G. Analysis of the microtopography of the skin by silicone replicas after repeated exposure to actinic radiation at high altitudes. J Eur Acad Dermatol 2001; 15: 224-8.

63 Nardin P, Nita D, Mignot J. Automation of a series of cutaneous topography measurements from silicon rubber replicas. Bioeng Skin 2002; 8: 112-7.

64 Glogau RG. Physiologic and structural changes associated with aging skin. Dermatol Clin 1997; 15: 555-9. 